\title{
O ENSINO DE LITERATURA BRASILEIRA NAS ESCOLAS: UMA FERRAMENTA PARA A MUDANÇA SOCIAL ${ }^{1}$
}

\author{
Gustavo Zambrano²
}

Resumo: Esse trabalho tem como objetivo realizar um detalhamento aprofundado das tensões externas que comprometem a educação no Brasil. Essas tensões dizem respeito ao golpe militar que inibiu melhorias no setor educacional, ao estudo exclusivo nas escolas de obras consideradas canônicas e ao estudo conteudista de literatura exigido pelos exames vestibulares. Esse é um debate importante, pois o ensino atual de literatura nas escolas impede a formação de estudantes capazes de analisar e interpretar um texto literário e de compreender o contexto histórico e sociológico de um país. Iremos, portanto, detalhar esses problemas e apresentaremos como o ensino de literatura brasileira pode ser importante para a percepção por parte dos alunos dos problemas sociais e consequentemente criar estudantes críticos.

Palavras-Chave: mudança social, cânone, vestibular, ensino de literatura brasileira

\begin{abstract}
This work aims to conduct an approach of the external stresses that affect education in Brazil. These tensions concern the military coup that inhibit improvements in the educational sector, the unique study in the schools of works considered canonical and set of topics literature study for entrance exams required. This is an important debate because the current teaching of literature in schools inhibits the formation of students able to analyze and interpret a literary text and understand the historical and sociological context of a country. We will therefore detail these problems and present how the teaching of Brazilian literature may be important for the perception of social problems by students and thereby stimulate a critical thinking.
\end{abstract}

Keywords: social change, canon, University entrance exam, teaching of Brazilian literature

A baixa qualidade do ensino de literatura brasileira ou até mesmo a ausência dessa disciplina na grande maioria das escolas públicas se deve a vários fatores

\footnotetext{
${ }^{1}$ Este trabalho consiste em uma atividade realizada para a disciplina FLC0601 - Ensino de literatura brasileira, ministrada pelo Prof. Jaime Ginzburg, do DLCV-FFLCH-USP, no primeiro semestre letivo de 2014

${ }^{2}$ Discente em Letras na Universidade de São Paulo. E-mail: gustavo.zambrano@usp.br 
conservadores presentes no sistema educacional brasileiro e na sociedade de nosso país. Como observou Florestan Fernandes (1966a) em seu estudo "A Crise do ensino" não há nas escolas um mau aluno, mas um mau ensino. O pensamento de Florestan Fernandes (1966a) se deve em razão de as escolas e consequentemente o ensino de literatura estarem desvinculados a uma função social. Acerca dessa questão, Fernandes (1966b), em outro artigo, "Mudança social e educação escolarizada", desenvolve a tese de que as instituições de ensino têm a responsabilidade de apresentar funções sociais inovadoras, para então instituir, no homem, a capacidade de percepção e a inteligência criadora (Fernandes, 1966b, p.86). No entanto, para Fernandes (1966b) as escolas a partir do golpe militar, e nos parece que também nos dias atuais, estão desvinculadas das questões sociais e consequentemente não conseguem formar cidadãos capacitados para propor mudanças para o país. Esse nos parece ser um debate importante e que merece detalhes mais apurados.

A partir da década de 40, o Brasil começa a sofrer algumas modificações econômicas e sociais. Há nesse período o início do processo de desenvolvimento econômico, sendo que a modernização da produção rural e a industrialização dos grandes centros urbanos se faziam necessárias. O país procurava, portanto, se adequar a uma economia capitalista. No entanto, esse desenvolvimento capitalista fora controlado e consequentemente favorecido a somente uma parcela da população, ou seja, aos integrantes das altas classes sociais. Como explica Fernandes, "O fluxo da mudança social trazia em seu bojo novas formas de organização institucional das atividades econômicas, sócio-culturais e políticas, as quais foram amplamente absorvidas e controladas pelos setores senhoriais ou quase senhoriais que compunham a referida ordem civil (no campo e nas cidades)" (Fernandes, 1974, p.41). Assim, o desenvolvimento que ocorria no início da década de 40 , seja no âmbito econômico, político e cultural, não favorecia a grande parcela da população, mas a uma pequena minoria privilegiada.

O conservadorismo no período da década de 30 e 40 no Brasil não atingia somente os setores políticos, econômicos e sociais, mas também o plano educacional. Nesse período de governo de Getúlio Vargas havia a preocupação de formar "uma elite mais ampla, intelectualmente mais bem preparada" (Fausto, 2003, p.336). Em outras palavras, Fausto (2003) afirma que "o Estado tratou de organizar a educação de cima para baixo, mas sem envolver uma grande mobilização da sociedade" (Fausto, 2003, p.337). Assim, nos parece que apesar de no período de governo de Getúlio Vargas existir um aumento do número de alunos nas escolas, como enfatizou 
Gustavo Capanema, ministro da educação de Vargas, (Schwartzman, 1983, p.355) esse crescimento não envolveu a grande parcela da população, mas os indivíduos pertencentes à elite.

A tentativa de aproximação do sistema educacional brasileiro com os mais diversos setores da população, somente ocorreu ao final do governo de João Goulart (Freitas \& Biccas, 2009, p.240). De acordo com os estudiosos citados, primeiramente fora criada pelo então ministro da educação, Paulo de Tarso, a Comissão de Cultura Popular, sendo que essa tinha como função a implantação em todo o país de sistemas educacionais totalmente populares. Na sequência de criação de planos ligados à educação, coube ao educador Paulo Freire criar as Comissões Regionais de Cultura Popular, cujo objetivo era "[...] incentivar pesquisas nas áreas ligadas à promoção da cultura popular, tais como folclore, teatro, cinema, música, etc. Predominou, no entanto, a concentração de esforços e recursos destinados à educação" (Freitas \& Biccas, 2009, p. 240). Nesse período, início dos anos 60, também por iniciativa de Paulo Freire, criou-se o Movimento de Educação de Base, também conhecido como MEB. Segundo Freitas \& Biccas (2009), o MEB tinha a visão de que somente com a educação era possível transformar a mentalidade das pessoas e a estrutura do sistema. O MEB, portanto, "colocou-se [...] ao lado dos mais pobres, defendendo a promoção humana por meio da conscientização, como única possibilidade de participação na vida política, econômica e social" (Freitas \& Biccas, 2009, p. 242).

Com o golpe militar de 1964, o sistema educacional brasileiro novamente será visto de cima para baixo. A política para a educação nesse período terá como regra o "desenvolvimentismo, produtividade, eficiência, controle e repressão" (Hilsdorf, 2003, p.124). Como consequência dessa política educacional os aspectos qualitativos foram colocados em segundo plano, assim como, qualquer possibilidade da educação em geral (escolas, universidades) estar atrelada a um contexto social. O período ditatorial no Brasil foi, portanto, uma forma de pressão externa às melhorias da educação. Qual o motivo, portanto, para a recusa ao avanço educacional? A razão diz respeito ao fato de que os professores das ciências humanas são dispensáveis a um sistema político que privilegia a repressão. Como explica Chauí (2001, p.161) os professores das humanidades eram vistos como adversários e um perigo importante para a sociedade em geral. Além do mais, a atitude repressora do governo ditatorial trará conseqüências danosas nas carreiras de humanidades, sendo que essas permanecem até os dias atuais. Marilena Chauí (2001, p.161-162) explica, por exemplo, que no período entre 1974 e 1985 ocorre a reformulação do ensino dos cursos de Letras e Ciências Sociais a partir do surgimento das licenciaturas curtas, a eliminação da disciplina de filosofia 
nos cursos de segundo grau, o auto investimento em escolas técnicas e pouco investimento nas escolas normais, entre outros.

Se o governo ditatorial foi uma pressão externa que impedia o desenvolvimento e melhorias da educação no país, hoje o sistema educacional brasileiro continua sofrendo com diversas pressões externas, o que dificulta qualquer possibilidade de mudanças por parte dos educadores. Como explica Fernandes (1966b, p.94)

Os educadores de tendência inovadora encontram, eventualmente, ocasiões propícias para introduzir mudanças básicas em nossa política educacional. Mas não contam com meios para resguardar as inovações, tendo de assistir impotentes à deformação das medidas construtivas preconizadas ou de acomodar-se às forças que propugnam pela preservação de concepções educacionais anacrônicas, associando-se assim aos fatores de nosso atraso educacional.

No trecho acima, Florestan Fernandes (1966b) afirma existir forças e concepções educacionais anacrônicas que impedem as mudanças educacionais necessárias. Essas forças e concepções retrógradas nada mais são do que pressões externas criadas direta ou indiretamente pelos integrantes do poder político avesso às inovações.

Afirmamos anteriormente que a ditadura foi uma pressão externa ao sistema educacional. Nos dias atuais, quais seriam essas pressões? Nos parece que as pressões externas estão relacionadas com os temas que envolvem o problema do cânone, do saber reprodutivo e do ensino de literatura totalmente afastado da realidade social. Vejamos cada uma delas.

Pierre Bourdieu (1999) em seu estudo "A excelência e os valores do sistema de ensino francês" afirma existir dois perfis de alunos: o opaco e o brilhante. Em relação ao primeiro, Bourdieu (1999) afirma ser esse aluno submisso ao pensamento canônico e reprodutor daquilo que é transmitido pelo professor. Já o aluno brilhante, além de dominar o conhecimento canônico, demonstra ter uma vasta cultura. Bourdieu (1999) também explica que as "disciplinas canônicas consagram [somente] os alunos provenientes das famílias mais favorecidas tanto pela situação social como pelo nível cultural [...]" (Bourdieu, 1999, p. 238). A partir dos apontamentos de Bourdieu (1999), 
observamos que o cânone além de ser um elemento que favorece a cristalização de um sistema educacional conservador, é responsável pela exclusão de alunos menos favorecidos no momento da busca de oportunidades educacionais. Como ocorreria, portanto, essa exclusão? Roberto Reis (1992) em seu texto "Cânon" observa que a ideia de cânone está relacionada com o princípio de seleção e poder. O crítico literário explica que os responsáveis pela canonização e exclusão de uma obra "estão investidos da autoridade para fazê-lo e o farão de acordo com os seus interesses (isto é: de sua classe, de sua cultura, etc.)" (Reis, 1992, p.70). Como consequência desse processo de seleção de obras literárias, ocorrerá o esquecimento e o não estudo/leitura de obras que foram produzidas em outras culturas, tais como a africana e a indígena, ou por grupos marginalizados, mulheres, etnias não-brancas e minorias sexuais (Reis, 1992, p.72-73). Se tomarmos o sistema educacional brasileiro como paradigma, observaremos que o estudo de literatura brasileira nas escolas estabelece um modelo canônico, excluindo do ensino o estudo e a oportunidade de discussões que envolvessem culturas populares, seja ela no campo da música, do teatro e da literatura. Isso se deve em razão de que as escolas procuram ensinar aquilo que estabelece as provas vestibulares, ou seja, as escolas abordam em seus programas de ensino obras e autores considerados canônicos. Com isso, no momento do exame vestibular, somente ingressarão nas Universidades os alunos de escolas particulares que têm conhecimento dessas obras. Já os alunos das escolas públicas, que tem o conhecimento das culturas populares, terão maior dificuldade de ingresso, haja vista que o ensino de literatura em suas escolas é deficitário, ou seja, não se ensina as obras canônicas de vestibular, além de não ocorrer nesse exame a abordagem de temas populares que esses alunos dominam. Sobre a questão do cânone, entendemos que as escolas sejam elas públicas e particulares devem apresentar em seus currículos as obras consideradas canônicas, pois a abordagem dessas obras em aulas é uma maneira de se dialogar com o contexto contemporâneo e de relacionar com os problemas sociais. Tomemos como exemplo o livro "Vidas Secas", publicado por Graciliano Ramos em 1938. Nessa obra, observamos a viagem sem rumo da família de Fabiano e a tentativa dos familiares em sobreviver no meio da miséria do sertão nordestino da década de 30 . Essa nos parece ser uma questão importante no momento da análise e interpretação dessa obra em sala de aula. O professor nesse momento poderia abordar o problema social existente no começo do século passado e questionar se a desigualdade social e o subdesenvolvimento ainda prevalecem nos dias atuais em regiões do Brasil. Seguindo o mesmo raciocínio, a reflexão dos problemas sociais brasileiros também pode ser abordado a partir do estudo da obra "Caçadas de Pedrinho", de Monteiro Lobato. Como sabemos, essa obra foi em 2010 
alvo de críticas, em razão de apresentar conteúdos de teor racista, como, por exemplo, nas passagens em que Tia Nastácia é denominada pelo narrador como "pretura", aquela que tem "carne preta" e "macaca de carvão". A partir da leitura da obra, observamos, então, um forte conteúdo racista na obra de Monteiro Lobato. O professor caso escolha abordar essa obra nas aulas de literatura brasileira deve ter em mente dois questionamentos: o primeiro é se um clássico da literatura brasileira colaboraria para que os alunos do ensino fundamental ou médio compreendessem, a partir da mediação do professor, as questões que envolvem o racismo; já o segundo qual a melhor forma de se abordar a obra de Lobato em sala de aula. Em relação ao primeiro questionamento, nos parece que "Caçadas de Pedrinho" deveria ser abordada com alunos do ensino médio, pois esses estudantes já têm idade para compreender a noção de tempo histórico (Eisenberg; Junior; Nascimento 2013, p.94), ou seja, entender que o conteúdo racista presente no texto de Monteiro Lobato era algo aceitável para o período em que a obra fora escrita, mas totalmente inadmissível nos dias atuais. Já o segundo questionamento, diz respeito à contextualização do momento em que a obra de Monteiro Lobato fora escrita. Nos parece que no estudo de "Caçadas de Pedrinho", surge a oportunidade ao professor em abordar as questões socais da década de 20 e 30, explicando aos alunos a informação de que no período de publicação da obra, início do século $X X$, no Brasil havia a teoria científica de Oliveira Viana. Como sabemos, Viana defendia o pressuposto de que uma raça sem aprimoramento não sobrevive e que o negro não tem capacidade para evoluir. Essa contextualização do momento histórico e social brasileiro durante a década de 30 nos parece ser importante no momento do aluno refletir acerca do racismo e para o desenvolvimento do debate: o racismo ainda predomina nos dias atuais? O que pode ser feito para mudar essa realidade?

Por outro lado, entendemos também existir a possibilidade de se desenvolver na sala de aula, um estudo entre obras canônicas e obras não canônicas escritas pelos integrantes dos mais diversos segmentos culturais. O texto elaborado pelo MEC que estabelece as orientações curriculares para o ensino médio defende a leitura de obras canônicas e não canônicas pelos estudantes do ensino médio. O texto diz: "Pensamos que se deve privilegiar como conteúdo de base no ensino médio a Literatura Brasileira, porém não só com obras de tradição literária, mas incluindo outras, contemporâneas significativas" (MEC, 2006, 73-74).

No entanto, apesar da recomendação do MEC em muitas escolas públicas não há um programa de ensino em que se estabeleça o diálogo entre uma obra 
canônica e contemporânea ou somente o estudo de uma obra contemporânea importante. Caso houvesse um programa de ensino em que ocorresse o estudo de duas obras, canônica e não canônica, como poderia ocorrer a abordagem dessas obras em sala de aula? Tomemos novamente como exemplo a obra "Vidas Secas". O romance de Graciliano Ramos, que como afirmamos apresenta o subdesenvolvimento da região nordestina e a vida penosa do sertanejo dessa região, pode ser comparado, por exemplo, com o conto "Muribeca", de Marcelino Freire e que está contido no livro "Angu de Sangue". Nesse conto é apresentado ao leitor a história de uma catadora de lixo que trabalha em um aterro sanitário e desse local retira o seu sustento. Assim, com o estudo de uma obra canônica e outra não canônica contemporânea o professor de literatura pode mostrar aos alunos que o subdesenvolvimento não foi sanado até os dias atuais, surgindo, portanto, como tema na literatura brasileira contemporânea.

Por fim, acerca do estudo de obras canônicas e não canônicas, o professor pode ainda ensinar aos alunos as particularidades de cada obra a partir dos aspectos formais, tais como o estudo do narrador, do tempo, do espaço, dos personagens e do foco narrativo. Seria importante, por exemplo, ensinar aos estudantes que as obras canônicas de tempos passados têm narrativas lineares, enquanto que as obras atuais podem apresentar narrativas mais fragmentadas.

Como vimos no início desse trabalho, com o golpe militar de 1964 se procurou consolidar uma política educacional em que se privilegiava o saber reprodutivo, e isso envolve um saber de grandes conteúdos, do que um saber que privilegiasse a qualidade do ensino. Nos parece, que essa postura equivocada do saber conteudista ainda vigora nos dias atuais, principalmente se tomarmos como paradigma os livros didáticos que versam sobre a disciplina de literatura, além do formato das aulas de literatura praticado nas escolas. Em relação aos livros didáticos de literatura, uma análise apurada é possível observar que esses materiais apresentam diversos problemas, tais como resumos de conteúdos, ausência de ideias para se desenvolver um raciocínio, grande presença de estereótipos, ausência de contextualização dos temas e o fortalecimento da canonização de autores já consagrados. Acerca dos materiais de ensino de literatura, Ginzburg (2012a, p.213), no artigo "O ensino de Literatura como Fantasmagoria", explica ainda que nesses materiais não há espaço para debates críticos sobre uma obra, sendo que aquilo que é priorizado são as classificações, descrições e simplificações. Além desses problemas que se apresentam nos livros didáticos, podemos citar também a existências nesses materiais de fragmentos de textos literários. Esse nos parece ser um problema grave, pois com a fragmentação de trechos das obras literárias não se valoriza o debate, a reflexão |34| Ensino de Literatura em Perspectiva Crítica - Agosto de 2015 - ISSN 1679-849X http://cascavel.ufsm.br/revistas/ojs-2.2.2/index.php/LA/index 
acerca de uma sociedade, a polissemia, as interpretações e a prática de leitura das obras em sua totalidade. Já em relação ao formato das aulas de literatura brasileira nas escolas, encontramos um ensino em que o foco é o estudo da história da literatura, ou seja, o estudo das escolas literárias. Com isso, o professor de literatura das escolas somente prepara o aluno para as provas de Vestibular, deixando de lado a preocupação em formar leitores que sejam capazes de analisar e interpretar uma obra literária. É necessário rever o ensino de literatura brasileira nas escolas. Como explica Cyana Leahy-Dios, "As questões de voz e representação nas aulas de educação literária no Brasil exigem uma revisão do cânone, dos programas de conteúdos e dos métodos didáticos que estão imbricados e tecidos na política do país" (Leahy-Dios, 2000, p.204).

Qual seria, portanto, o método de ensino ideal em um curso de literatura, tendo em vista a formação de alunos capazes em analisar e interpretar um texto literário e ao mesmo tempo desenvolver o seu potencial crítico? Nos parece que o ensino de literatura deva ser abordado nas escolas a partir do estudo dos conceitos de forma e conteúdo, além dos aspectos que envolvem a contextualização.

Antonio Candido (1972, p.82) no artigo "A literatura e a formação do homem" explica que a literatura desperta no homem o interesse pelos elementos contextuais $\mathrm{e}$ que a partir desses somos levados a conhecer a nossa própria identidade e o nosso destino:

[...] a literatura desperta inevitavelmente o interesse pelos elementos contextuais. Tanto quanto a estrutura, eles nos dizem de perto, porque somos levados a eles pela preocupação com a nossa identidade e o nosso destino, sem contar que a inteligência da estrutura depende em grande parte de se saber como o texto se forma a partir do contexto [...].

Já no artigo "O Direito à Literatura", Antonio Candido (2011, p.178-179) ensina que a literatura tem a capacidade de humanização, ou seja, fazer com que o homem perceba e reflita sobre o mundo, sobre o seu semelhante, sobre a sociedade em geral. Para que ocorra o caráter humanizador a partir da literatura é necessário que ocorra simultaneamente três faces: "(1) ela (literatura) é uma construção de objetos autônomos como estrutura e significado; (2) ela é uma forma de expressão, 
isto é, manifesta emoções e a visão do mundo dos indivíduos e dos grupos; (3) ela é uma forma de conhecimento, inclusive como incorporações difusa e inconsciente". Em outras palavras, para Candido $(1972,2011)$ um texto literário não se estabelece somente por uma estrutura interna, mas também por um conteúdo, sendo que esse se configura a partir da forma (elementos internos). Além do mais, com o estudo de um texto literário a partir da relação entre forma e conteúdo será possível observar e refletir de maneira clara os aspectos temáticos e os problemas abordados na obra. Em "Vidas Secas", o estudo do aspecto formal da narração pode ser um importante elemento estrutural capaz de evidenciar a miséria intelectual de Fabiano, ou seja, o pouco domínio da linguagem. Como afirma Ginzburg (2012b, p.195) é através do narrador que observamos as percepções de Fabiano. Mas qual é o recurso estrutural utilizado para evidenciar a percepção e o pensamento de Fabiano? O recurso utilizado é o discurso indireto livre, técnica narrativa essa em que as vozes do narrador e do personagem se confundem. Assim, a partir do estudo do discurso indireto livre e da explicação acerca da convergência solidária das vozes do narrador e do personagem, o professor de literatura no momento de análise e interpretação da obra deve fazer com que os seus alunos reflitam acerca de como o elemento estrutural é capaz de evidenciar a limitação do personagem Fabiano.

Por fim, a contextualização, ou seja, a apresentação de dados externos ao texto é um conceito que não pode deixar de ser abordado nas aulas de literatura. Nos parece que o conhecimento aprofundado do contexto histórico ou sociológico favorecerá uma interpretação adequada do conteúdo de uma obra pelo leitor. Nosso pensamento vai de encontro ao que formula Luiz Costa Lima (2006) no artigo "Letras à míngua". De acordo com o crítico a "drástica separação [da literatura] de áreas vizinhas, sobretudo da filosofia e da antropologia, Ihe é catastrófica" (Costa Lima, 2006, p.2). Costa Lima (2006) ainda explica que "a escassez da reflexão teórica ajuda a que se perpetuem os juízos críticos tradicionais" (Costa Lima, 2006, p.3). O tema abordado pelo crítico literário nos parece ir de encontro à questão do ensino de literatura brasileira como ferramenta de mudança social. Como estudar uma obra da literatura brasileira sem conhecer os dados externos a ela, ou seja, o contexto histórico e sociológico? Além do mais, nos parece que conhecer o contexto externo a obra literária é fundamental para que ocorra o debate em sala de aula, favorecendo a capacidade crítica do aluno. Tomemos novamente como exemplo a obra "Vidas Secas". Jaime Ginzburg (2012b, p.195), no texto, "Literatura e Direitos Humanos: notas sobre um campo de debates", explica: 
O distanciamento com relação aos recursos linguísticos necessários para firmar transformações sociais é um fato decisivo na sociedade brasileira. Aquilo que em alguns momentos Macabéa e Fabiano exibem de maneira extrema está difundido - historicamente e contemporaneamente -, no país, em variados graus: a falta de condições de expressão da própria dor.

Nos parece que o problema da falta de recursos e da limitação intelectual de Fabiano e de Macabéa são questões importantes a serem debatidas com os alunos. É necessário em sala de aula evidenciar que os problemas apresentados nos romances citados ainda existem na sociedade brasileira, o que torna um obstáculo para as transformações sociais e desenvolvimento do país. Assim, temos a opinião de que conhecer as características de uma escola literária é importante. No entanto, o ensino de literatura nas escolas não deve ficar limitado a esse programa de ensino. Entendemos que o ensino da disciplina de literatura brasileira deve-se basear principalmente no estudo dos elementos estruturais da narrativa ou da lírica, além dos elementos que envolvem o contexto. Dessa forma, o aluno estará apto a realizar de forma consistente a análise e interpretação do texto literário e consequentemente desenvolver a sua capacidade crítica.

Antonio Candido (2011) nos ensina que a literatura é um direito do cidadão, tendo ela a forte capacidade de humanização, de instruir e de educar. Como consequência, a literatura é capaz de apresentar e de denunciar os problemas da sociedade. Conhecendo essa característica dos textos literários, os governos conservadores procuram estabelecer políticas educacionais também conservadoras, ou até mesmo reacionárias, tornando os estudos literários cada vez mais dispensáveis. Para mudar essa triste realidade é necessário que os próprios professores de língua portuguesa dos níveis fundamentais e médios comecem, dentro da sala de aula, a propor mudanças acerca do ensino de literatura. Como explica Jeanne Marie Gagnebin no ensino de filosofia e nos parece que também no ensino de literatura não se pode temer os desvios ou a errância. Além do mais, acreditamos que o professor não deve temer as pressões externas, estando sempre aberto às inovações. As pressões externas impostas por políticas educacionais conservadoras ou até mesmo pressões criadas pelas escolas, essas não devem ser motivo de desconforto aos professores. O medo ou até mesmo receios que as pressões podem causar na vida profissional do professor devem dar espaço para uma postura corajosa 
e de inovação do ensino de literatura como ferramenta de percepção e mudança da sociedade.

\section{Referências Bibliográficas}

BOURDIEU, Pierre. A excelência e o sistema de valores do ensino francês. In: A economia das trocas simbólicas. São Paulo: Perspectiva, 1999.

CANDIDO, Antonio. O direito à literatura. In: Vários Escritos. Rio de Janeiro: Ouro Sobre Azul, 2011.

A literatura e a formação do homem. Revista Ciência e Cultura, v.24, ำ9, 1972.

CHAUÍ, Marilena. O mal estar na universidade. In: Educação e sociedade no Brasil. São Paulo: Edusp, 1966.

COSTA LIMA, Luiz. Letras a míngua. Folha de São Paulo, Mais! São Paulo, 27 de Agosto de 2006.

EISENBERG, Zena Winona; JÚNIOR, João Feres; NASCIMENTO, Leonardo Fernandes. Monteiro Lobato e o Politicamente Correto. Dados - Revista de Ciências Sociais. Rio de Janeiro, v.56, n.1, 2013.

FAUSTO, Boris. História do Brasil. São Paulo: Edusp, 2003. 
FERNANDES, Florestan. A crise do ensino. In: Educação e sociedade no Brasil. São Paulo: Edusp, 1966a.

Mudança social e educação escolarizada. In:

Educação e sociedade no Brasil. São Paulo: Edusp, 1966b.

. Mudanças sociais no Brasil. São Paulo: Difel, 1974.

FREIRE, Marcelino. Angu de Sangue. São Paulo: Ateliê Editorial, 2000.

FREITAS, Marcos Cezar de; BICCAS, Maurilane de Souza. História Social da Educação no Brasil (1926-1996). São Paulo: Editora Cortez, 2009.

GAGNEBIN, Jeanne-Marie. O método desviante. Revista Trópico. http://www.revistatropico.com.br/tropico/html/textos/2807,1.shl. Acesso em 20/05/2014.

GINZBURG, Jaime. O Ensino de Literatura como Fantasmagoria. Revista Anpoll. Florianópolis, SC, V.1, № 33, 2012a.

Literatura e Direitos Humanos: Notas sobre um campo de

Debates. In: . Crítica em tempos de violência. São Paulo, Edusp/Fapesp, 2012b.

HILSDORF, Maria Lucia Spedo. Da Ditadura Militar aos nossos dias. In:

História da Educação Brasileira: Leituras. São Paulo: Pioneira Thomson Learning, 2003. 
LEAHY-DIOS, Cyana. Conceituando dificuldade em educação literária. In: Educação literária como metáfora social. Niterói: Ed. UFF, 2000.

LOBATO, Monteiro. Caçadas de Pedrinho. São Paulo: Editora Brasiliense,1977.

MEC. Orientações curriculares para o ensino médio. Linguagens, códigos e suas tecnologias. Brasília: Ministério da Educação - Secretaria de Educação Básica, 2006.

RAMOS, Graciliano. Vidas Secas. Rio de Janeiro: Record, 2008.

REIS, Roberto. Cânon. In: Jobim, José Luís (org). Palavras da crítica. Rio de Janeiro: Imago, 1992.

SCHWARTZMAN, Simon (org). Estado Novo, um Auto-Retrato. Brasília: Editora Unb, 1983. 